\title{
EL NEGOCIO FUNDACIONAL EN LAS SOCIEDADES COOPERATIVAS DE PARTICIPACIÓN PÚBLICA
}

\author{
POR \\ Encarnación GARCÍA RUIZ ${ }^{1}$
}

\section{RESUMEN}

En este trabajo se analiza en que aspectos pueden verse alterados los elementos esenciales de consentimiento, objeto y causa del negocio fundacional de una sociedad cooperativa cuando participa como socio un ente público, así como la influencia que puede tener la naturaleza pública del socio en cada una de las clases de sociedad cooperativa previstas en la leyes de cooperativas y, cual sería la clase de socio de los concebidos legalmente más idóneo para participar los entes públicos en estas sociedades. Partimos del hecho de considerar que estas figuras organizativas son idóneas para la consecución de los fines propuestos por la acción Administrativa, dado que los valores que están en el sustrato de estas figuras jurídico privadas casan perfectamente con los objetivos de interés general perseguidos por las Administraciones públicas. No obstante, nuestro interés es concluir si fuera necesario reivindicar una categoría propia y específica para este subtipo, cuyo régimen jurídico previera las posibles peculiaridades que la naturaleza pública de uno de los socios puede plantear, a fin de garantizar de forma clara e indubitada, que la forma jurídica privada del tipo societario se corresponde con la atribución de personalidad jurídico privada que le es propia, para que ésta no pueda ser de hecho desplazada por la personalidad jurídico pública del ente administrativo que, entonces, a la postre, estaría actuando por persona jurídico privada interpuesta. Para ello nos hemos apoyado principalmente en la legislación jurídico pública que regula al ente público y la jurídico privada que regula a la sociedad, ambas convergen en estas figuras societarias de participación pública.

\footnotetext{
${ }^{1}$ Profesora Contratado Doctor de Derecho Mercantil. Universidad de Almería. Dirección de correo electrónico: egruiz@ual.es
}

REVESCO Nº 111 - Segundo Cuatrimestre 2013 - ISSN: 1885-8031 - www.ucm.es/info/revesco

http://dx.doi.org/10.5209/rev_REVE.2013.v111.426752

Fecha de recepción: 09/01/2013

Fecha de aceptación: 05/04/2013 
Palabras clave: Administraciones Públicas, formación de la voluntad del ente público como socio público, fines sociales públicos, objeto social, naturaleza de la aportación pública.

Claves Econlit: K 200; L 320; L 330; L 390

\title{
THE FOUNDATIONAL BUSINESS IN THE COOPERATIVES SOCIETIES OF PUBLIC PARTICIPATION
}

\begin{abstract}
In this work it is analyzed in that aspects can there turns altered the essential elements of assent, object and reason of the business foundational of a cooperative company when it he informs as partner a public entity, as well as the influence that can have the public nature of the partner in each one of the classes of cooperative company foreseen in the leys of cooperatives and which would be the class of the most suitable partner to inform the public entities in these societies. We depart from the fact of to consider that these organizational figures are suitable for the attainment of the ends proposed by the Administrative action, provided that the values that are in the juridical substratum of these private figures marry perfectly the aims of general interest chased by the public Administrations. Nevertheless, our interest is to conclude if it was necessary to claim an proper and specific category which juridical regime was foreseeing the possible peculiarities that the public nature of one of the partners can raise In order to guarantee of clear form and indubitable that the juridical private form corresponds with the attribution of juridical private personality that him is proper in order that this one could not be of fact displaced by the personality juridical public of the administrative entity that, at last, would be acting for person juridical. For it we have rested principally on the legislation juridical public that regulates to the public entity and her juridical deprived that it regulates to the society, both converge on these association figures of public participation.
\end{abstract}

Key words: Cooperative societies, government, training of the will of the public entity or public partner, public social purposes objects, nature of public input. 


\section{INTRODUCCIÓN}

La participación de las Administraciones públicas en el movimiento cooperativista puede realizarse en dos direcciones. Una dirección es mediante el fomento del mismo, dando así cumplimiento al mandato constitucional que obliga a los poderes públicos a promover eficazmente las diversas formas de participación en la empresa y a fomentar, mediante una legislación adecuada, las sociedades cooperativas (art. 129.2 C.E.). Ese desarrollo legislativo se ha realizado mediante la Ley 27/1999, de 16 de julio, de cooperativas que "reconoce como tarea de interés general, a través de esta Ley y de sus normas de aplicación, la promoción, estímulo y desarrollo de las sociedades cooperativas y de sus estructuras de integración económica y representativa" (art 108.1 Ley 27/1999, en adelante LCOOP). Y, también por cada una de las Leyes Cooperativas de las distintas Comunidades Autónomas, dada la organización territorial de nuestro país en Comunidades Autónomas y su distribución competencial. Esto último es una dificultad añadida al estudio del régimen jurídico de estas figuras cuando son de participación pública.

La otra dirección a la que nos referíamos es mediante la participación directa en la constitución de estas sociedades o participación en su capital de las ya constituidas. Esta dirección es la que va a ser nuestro objeto de estudio.

Las sociedades cooperativas son organizaciones idóneas para la consecución de los fines propios de la acción Administrativa, dado que los valores que están en el sustrato de estas figuras jurídico privadas casan perfectamente con los objetivos de interés general perseguidos por las autoridades públicas como, por ejemplo, políticas de empleo, cohesión social y territorial, atención a personas discapacitadas, integración de personas en riesgo de exclusión social, etc. Aunque no necesariamente, como veremos más adelante, la participación de un ente público en estas empresas tiene que limitarse a la consecución de fines sociales, pues las cooperativas son sociedades que pueden perseguir cualquier objetivo empresarial.

Para el ente público- socio público, (en adelante socio público), el régimen jurídico de las cooperativas es ventajoso porque limita su responsabilidad a lo aportado, ${ }^{2}$ y puede

\footnotetext{
${ }^{2}$ Dada la personalidad jurídica única de la Administración y las consecuencias de ello en orden a la responsabilidad, ésta no puede participar en ninguna sociedad mercantil cuyo régimen jurídico no limite la responsabilidad del socio a lo aportado. De ello deja constancia expresa, por ejemplo, el artículo 106 del Real Decreto Legislativo 781/1986, por el que se aprueba el Texto Refundido de las Disposiciones Legales vigentes
}

REVESCO No 111 - Segundo Cuatrimestre 2013 - ISSN: 1885-8031 - www.ucm.es/info/revesco 
conseguir fines de interés general a través de una organización jurídico privada más humanizada que las sociedades típicamente capitalistas. Aunque, como todo, tiene su reverso, las desventajas de estas figuras mercantiles para el socio público puede residir en que, quedan sometidas a un régimen más complejo debido a los principios cooperativos que deben cumplir; no pueden ser unipersonales; el reparto de beneficios está condicionado legalmente; no pueden ser titulares de la mayoría del capital social de forma directa en las cooperativas de primer grado, etc. A pesar de esto, las últimas reformas legales han introducido en el régimen jurídico de las mismas, elementos configuradores de las sociedades típicamente capitalistas, como las anónimas y limitadas que las acerca al régimen jurídico de estas últimas, lo que, en cierto modo, puede favorecer al socio público, en orden a preservar el equilibrio entre sus obligaciones como socio y como Administración.

Como hemos avanzado ya, la dificultad en el estudio de esta figura nos vendrá dada por la diversidad de leyes cooperativas que hay que manejar y por la naturaleza pública del socio, que se rige por normas de derecho administrativo que hay que tener en cuenta para determinar su estatuto jurídico como socio público. Ambas normas, las públicas y las privadas deben considerarse conjuntamente para establecer el régimen jurídico de la figura organizativa resultante.

Precisamente lo que nos proponemos en las páginas siguientes es determinar como puede quedar afectada una sociedad cooperativa si participa en su constitución un socio público. Para ello hemos seguido la estructura de la Ley de Cooperativas estatal, a la que haremos las salvedades oportunas introducidas por otras leyes de cooperativas de comunidades autónomas y las normas administrativas referidas a la Administración general del Estado cuando ésta o sus entes participen en una sociedad mercantil.

La primera ausencia que destacamos es que la LCOOP carece de referencias significativas a esta posibilidad. Solo su Exposición de motivos se refiere a la eventualidad de que los estatutos sociales posibiliten el voto plural ponderado en caso de entidades públicas, para sólo ser mencionado en su parte dispositiva por algunos artículos; así el artículo 12 recoge, que socio puede ser también una persona jurídica pública; el artículo 89 que se refiere a las cooperativas de vivienda; el artículo 106.2 a las cooperativas de iniciativa social o la

en materia de régimen local, que se expresa en los siguientes términos: "En las sociedades mercantiles o cooperativas..... la responsabilidad de la Entidad local se limitará a lo que expresamente conste en la escritura de constitución, sin que, en ningún caso, sea inferior al valor de los bienes o derechos aportados por aquélla."

REVESCO No 111 - Segundo Cuatrimestre 2013 - ISSN: 1885-8031 - www.ucm.es/info/revesco 
Disposición Adicional primera de la LCoOP. Tampoco vienen en nuestro auxilio las leyes cooperativas de las comunidades autonómicas, que también recogen la posibilidad del socio público pero ninguna recoge un posible régimen específico en estos casos. Este silencio legal no puede llevarnos al error de considerar que no hay ninguna especialidad en las cooperativas de participación pública. ${ }^{3}$

Podemos avanzar ya que cualquier ente público necesita de un expediente administrativo de autorización para participar como socio en cualquier sociedad mercantil o para dejar de participar en ella. Ese expediente no solamente formará la voluntad privada de constitución del tipo, sino que contendrá elementos definidores propios de la estructura organizativa, tales como su participación en el capital, en la administración social, etc., Por otra parte, el régimen jurídico de este tipo de sociedades limita las posibilidades del socio público que, como ya hemos avanzado, no puede constituir una sociedad cooperativa unipersonal pública pero no hay inconveniente legal en que haya sociedades cooperativas de capital únicamente público o mayoritariamente público, cuando todos los socios son públicos o hay varios socios públicos y sumadas sus aportaciones de capital, éste es mayoritariamente público. Esto tiene como consecuencia que la sociedad cooperativa de capital mayoritariamente público quedará integrada en el sector público empresarial. Así lo disponen las normas administrativas, que consideran que formarán parte del sector público empresarial las sociedades mercantiles estatales, consideradas como tales las que tienen mayoría de capital público quedando sometidas a las especialidades previstas para ellas en las normas administrativas (art. 3.2,b, de la Ley 47/2003, de 26 de noviembre, General Presupuestaria, en adelante LGP). Y una sociedad cooperativa es una sociedad mercantil de acuerdo a lo dispuesto en la legislación mercantil.

\section{DE LA PARTICIPACIÓN DE UN ENTE PÚBLICO EN LA CONSTITUCIÓN DE UNA COOPERATIVA}

a. La formación de la voluntad de constituir del socio público

\footnotetext{
${ }^{3}$ Sirva de ejemplo de lo que decimos, lo dispuesto en el artículo 104.2 del Real Decreto Legislativo 781/1986, ya mencionado que establece que: "En el acuerdo constitutivo podrán establecerse las especialidades internas tanto estructurales como funcionales que, sin perjuicio de terceros, exceptúen la legislación societaria aplicable, en la medida necesaria para promover y desarrollar la empresa mixta de carácter mercantil o cooperativo".
}

REVESCO N 111 - Segundo Cuatrimestre 2013 - ISSN: 1885-8031 - www.ucm.es/info/revesco 
No cabe duda que el proceso fundacional de una sociedad cooperativa está investido de las dos dimensiones que se reconocen en la constitución de cualquier tipo de sociedad mercantil, la dimensión contractual y organizativa o institucional. En cuanto a la dimensión contractual, el negocio fundacional de una cooperativa donde participa un ente público queda regulado por el ordenamiento jurídico privado. Por cuanto, incluso, las sociedades mercantiles estatales, cualquiera que sea su forma jurídica, se someten al ordenamiento jurídico privado (Disposición Adicional duodécima de la Ley 6/1997, de 14 de abril, de Organización y Funcionamiento de la Administración General del Estado, en adelante LOFAGE), con mayor razón las sociedades cooperativas que directamente no pueden ser de capital único o mayoritariamente público. Sin embargo, ya hemos avanzado que la sociedad cooperativa es una sociedad mercantil que sería considerada como estatal en el hipotético caso que de forma indirecta sí tuviera la mayoría del capital público.

El negocio fundacional privado de la sociedad no lo podemos confundir con la formación de la voluntad del socio público, que se concreta en un expediente técnico de autorización previo al otorgamiento de la escritura de constitución y a su necesaria inscripción registral posterior, requisitos formales de constitución que les va a permitir a la sociedad actuar en el tráfico mercantil de forma regular como un ente personificado, separado y distinto de sus socios. Lo que se ha dado en llamar la dimensión organizativa o institucional de la sociedad en contraposición a la dimensión contractual.

Este procedimiento administrativo de formación de la voluntad del socio, al que nos referimos, obedece al principio de legalidad a que queda sometida la actividad de la Administración pública conforme al cual todas las competencias y obligaciones que ésta asume están previamente establecidas en las leyes o en sus normas de desarrollo (art. 103.1 $\mathrm{CE}$ ). Lo contrario no produciría efectos jurídicos y el procedimiento fundacional quedaría viciado respecto a este socio. Únicamente una ley puede conceder a la Administración potestad para actuar a la vez que acotará los límites y condiciones de su actuación. Esta técnica de concesión de poderes es la que otorga al ente público capacidad pública y privada necesaria para que intervenga como socio en una organización jurídico privada (art. 1,4 LOFAGE), al ser la ley de autorización un requisito indispensable del presupuesto de validez del consentimiento prestado por el socio público en el negocio jurídico de fundación. 
La peculiaridad del negocio fundacional de una sociedad cooperativa viene dada por que el consentimiento de uno de los socios, el público, necesita de esa previa cobertura legal para cualquier actuación administrativa (art. 9.1,3 y 103.1 CE y art. 3 y 54 LOFAGE), siendo una norma la que sustituye a la autonomía de la voluntad del socio privado para otorgar o no el consentimiento en el contrato de constitución de la sociedad, la que ha de atribuir la potestad de actuar para cada caso concreto, de forma que la Administración no podrá crear, modificar o extinguir relaciones jurídicas de derecho privado si previamente no ha sido habilitada para ello a través de la correspondiente atribución de potestad. Esta se plasma en un procedimiento técnico-jurídico concretando para cada caso concreto un principio general de admisión de su capacidad jurídico privada, que actúa en sustitución de lo que sería la formación de voluntad interna de un sujeto de derecho privado en la valoración de la conveniencia de decidir su vinculación a un concreto negocio fundacional de una sociedad. Por tanto, la capacidad del ente público para constituir una sociedad mercantil, en este caso una cooperativa, no se rige por el derecho privado común, sino por normas jurídico públicas.

No podemos olvidar que la Administración pública tiene personalidad jurídica única y se organiza, solo funcionalmente, en entes territoriales o institucionales con personalidad jurídica propia e independiente (art. 1 LOFAGE). Ello significa que un ente público solo puede participar en la constitución de una sociedad cooperativa si está autorizado para ello, porque no puede formar su voluntad de forma independiente a la Administración en la que se ubica. La legislación estatal habilita a la Administración General del Estado y a los Organismos públicos para fundar sociedades mercantiles (capítulo VII de la Ley 33/2003 de la Ley de Patrimonio de las Administraciones Públicas, en adelante LPAP y art. 62.1.f, LOFAGE), acordándose en el primer caso que la autorización para la creación de sociedades la otorgará el Consejo de Ministros (art. 169, f LPAP), mientras que, en el caso de los Organismos públicos, la autorización vendrá determinada por el contenido de sus estatutos.

El procedimiento administrativo que se concreta en el expediente técnico de autorización al que nos venimos refiriendo tiende, por un lado, a constatar la conveniencia de organizar una determinada actividad empresarial a través de una sociedad mercantil como la vía más adecuada para conseguir los fines públicos propuestos, a la vez que recoge la voluntad expresa en orden a posibilitar la constitución de una concreta sociedad mercantil, en lo que supone la formación de la voluntad electora del tipo. Por tanto, el fin propuesto para la futura sociedad queda, como hemos dicho, recogido en el expediente de autorización, ese fin 
se traslada al negocio jurídico privado de fundación, convirtiéndose en su elemento causal. La naturaleza pública o privada del fin propuesto no va a interferir o alterar el negocio jurídico privado de fundación toda vez que ha sido superada la necesidad de identificar el fin mercantil con el ánimo de lucro por un lado y, por otro, considerar que necesariamente la sociedad cooperativa no podía tener ánimo de lucro. Lo que queremos decir es que no podemos confundir la actividad a la que se dedique la sociedad cooperativa, el fin social concreto perseguido por la misma y la aplicación de los resultados. La actividad y los fines sociales perseguidos pueden ser de tan amplio espectro como en cualquier otra sociedad mercantil, mientras que el destino de los resultados económicos tendrá que respetar lo dispuesto en la normativa que regula el régimen jurídico de este tipo de sociedades.

b. La denominación social en las sociedades cooperativas de participación pública.

Junto al proceso de formación de la voluntad de constituir una sociedad cooperativa, hay que ubicar la elección por los socios de la denominación social de ésta. Nada dicen la LCoOP., ni el Real Decreto 136/2002, de 1 de febrero, por el que se aprueba el Reglamento del Registro de Sociedades Cooperativas (en adelante RRC), en torno a la formación de la denominación social y solo se refieren a ella para, por un lado, establecer la siglas que identifiquen al tipo y que necesariamente se incluirá en la denominación social elegida por los socios, aunque sí se recoge legislativamente la posibilidad de que puedan, vía reglamentaria, establecerse sus requisitos (art.1.3 LCOOP), y, por otro lado, para establecer la necesidad de obtener la certificación negativa de denominación para poder inscribir en el Registro de sociedades cooperativas la misma (art. 33 RRC). Ante la ausencia de normas específicas para el caso de que en una sociedad cooperativa participe uno o más socios públicos y dado la parquedad de lo dispuesto en las normas generales en torno a este tema, hay que considerar que estas denominaciones sociales se rigen por el principio de libertad de denominaciones que impera en nuestro sistema normativo con los únicos límites previstos en las normas generales y específicas. Sin entrar en las dificultades que plantea la identificación del tipo de cada una de las leyes de cooperativas de las comunidades autonómicas, nosotros solo llamaremos la atención aquí sobre la posibilidad, como sociedades mercantiles que son, de que las denominaciones sociales de cooperativas con participación pública queden exentas de la prohibición recogida en el artículo 405.2 del Real Decreto 1.784/1996, de 19 de julio, por el que se aprueba el Reglamento del Registro Mercantil, (en adelante RRM) que impide la 
formación de denominaciones con referencia a los adjetivos «nacional» o «estatal»; «autonómico», «provincial» o «municipal»; «oficial», salvo que el socio público ostente directa o indirectamente la mayoría del capital. Lo que puede ocurrir en el caso de que haya varios socios públicos y la suma de las participaciones de cada ente público de lugar a la mayoría del capital como público o socios privados, como sociedades mixtas o de capital público que junto a otros socios públicos adquieran la mayoría del capital social.

La opción de introducir en la denominación social alguna referencia a la procedencia del capital es voluntario, pero la información inmediata que transmite a los terceros es muy indicativa y puede ayudar, junto con la utilización que la Administración haga del régimen jurídico de la sociedad, a que ésta quede investida por esa impronta pública de la que gozan otros tipos de sociedades, como las anónimas públicas, y que ha sido recogido tradicionalmente por la doctrina y reconocido en sentencias judiciales. Tanto que, en algunos casos, el régimen jurídico de la forma organizativa fue desplazado e ignorado por la fuerza de la presencia del socio público al que se le exigía que se comportara como Administración pública investida de su «ius imperium» y no como un socio privado ligado solo al «ius gestión», sobre todo en materia de financiación, condiciones laborales y sociales, etc. El ente público que participa en una sociedad cooperativa no quiere que se le exija una responsabilidad social más allá de la típicamente mercantil, pues de lo contrario hubiera utilizado otra forma jurídico pública para intervenir en economía. Por tanto, debe ser el más interesado en respetar escrupulosamente el régimen jurídico elegido y no utilizarlo a su conveniencia, como ha hecho tradicionalmente con otros tipos societarios, principalmente con la sociedad anónima.

c. La sociedad cooperativa de participación pública en constitución.

Igualmente es importante llamar la atención sobre el periodo de tiempo en que la sociedad cooperativa esté en constitución. El régimen previsto en el artículo 9 de la LCoOP, es muy similar al de las sociedades de capital. El legislador muestra especial sensibilidad por proteger a los terceros de buena fé de los actos y contratos que la sociedad cooperativa haya realizado durante este periodo que está en constitución, y de los que no podría responder frente a terceros la sociedad como ente distinto y separado de sus socios, pues sólo goza de una aparente personalidad jurídica hasta que se produzca el acto formal de inscripción registral de la sociedad.

REVESCO N 111 - Segundo Cuatrimestre 2013 - ISSN: 1885-8031 - www.ucm.es/info/revesco 
La aplicación de lo dispuesto en el artículo 9 de la LCOOP durante el proceso de constitución requiere que el expediente técnico de autorización que recibe el futuro socio público para constituir prevea y distinga los dos actos de que se compone el proceso fundacional, otorgamiento de escritura pública e inscripción registral y su diferencia temporal. Es decir que el expediente reconozca la existencia de una sociedad cooperativa en constitución y autorice al socio público a disponer de la partida presupuestaria destinada a la aportación social, a pesar de que, con carácter general, los fondos públicos están sometidos a finalidad y no se puede disponer de los mismos hasta que no se aplique al destino para el que se aprobaron. Es decir, la Administración pública autorizante, que ha otorgado la potestad de constituir, deberá considerar que los fondos aportados han dejado de ser públicos desde el momento del otorgamiento de la escritura pública y considerarlos ya como aportación patrimonial de titularidad societaria, de la que no podría disponerse en otro caso, aunque aún no se haya cumplido el acto formal de inscripción, toda vez que las aportaciones de capital, aunque condicionadas a la inscripción, tienen que ser desembolsadas en el momento de otorgar la escritura pública pues, de lo contrario, el notario autorizante no elevará a escritura pública el contrato de sociedad si no se exhibe el resguardo del depósito bancario de la aportación. Por otro lado, tampoco se alteraría así el régimen de responsabilidad entre socios públicos y privados en este periodo, corriendo el riesgo el socio público que, aún no ha limitado su responsabilidad, de extender ésta a toda la Administración. Por todo ello sería conveniente que el expediente técnico de autorización concretara, además, qué facultades otorga la autorización administrativa y a quién autoriza expresamente en este periodo de formación y quién es responsable de los mismos, para que no haya confusión frente a terceros. De lo contrario, se puede crear cierta inseguridad jurídica al no saberse exactamente qué régimen jurídico se va a aplicar al socio público en este período de formación, si el privado o el público, pues puede plantearse la situación absurda de que el socio privado apruebe lo actuado por los promotores en este periodo de constitución, porque tiene plena capacidad para decidir por sí mismo, mientras que el socio público se vea enzarzado en un procedimiento administrativo nuevo para recibir autorización para aceptar o no actos y contratos celebrados antes de la inscripción de la cooperativa y distintos a los previstos en el artículo 9 LCOOP mencionado.

Por último, la inscripción registral no sólo es el acto con el que finaliza el proceso fundacional privado de la sociedad cooperativa, sino que, además, supone poder cerrar un 
procedimiento administrativo que se abrió con la autorización para constituir este tipo de sociedad mercantil y cuyo cumplimiento necesariamente tiene que producirse para dar por concluido el procedimiento jurídico administrativo que, además, está sometido a plazo y a finalidad.

\section{EL ENTE PÚBLICO COMO SOCIO PÚBLICO EN LAS DISTINTAS CLASES LEGALES DE SOCIEDADES COOPERATIVAS}

En función de la actividad cooperativizada el ente público puede participar como socio en cualquier sociedad cooperativa siempre que cumpla con los requisitos exigidos para ello, previstos en los estatutos sociales (art. 12 LCOOP). Lo anterior es casi la única referencia expresa a este tipo de socios que nos encontramos en el articulado de la ley estatal, lo que nos lleva a plantearnos varias cuestiones. De una parte, si la naturaleza pública del socio puede integrarse en el espíritu cooperativista o solo se acomodará a una estructura organizativa formando lo que se ha dado en llamar falsa cooperativa, (Gadea; Sacristán; Vargas, 2009: 43). De otra parte, si esa misma naturaleza le permite participar como socio en cualquier clase de cooperativas y acomodar los fines públicos a los privados o, por el contrario, la exclusión podría venir por vías distintas a las legales y, por último, qué clase de socio de las previstas en la ley se acomoda más a la naturaleza pública del socio.

a. La influencia de la naturaleza pública del socio en la sociedad cooperativa.

En cuanto a la primera cuestión planteada, exige partir del espíritu cooperativista clásico que exige la colaboración en un plano de igualdad de todos los asociados para conseguir satisfacer sus necesidades, dónde las cualidades de los socios imperan sobre el capital que aporten y cuyo funcionamiento "inter partes" debe ser democrático.

Es cierto que la técnica legislativa más actual permite organizar estructuras cooperativizadas con rasgos propios de las sociedades de capital, pero no hasta el punto de que aquéllas queden desnaturalizadas, por eso es preciso que cualquiera que sea la estructura societaria resultante, éstas deben de cumplir necesariamente con los principios formulados por la alianza cooperativa internacional (art. 1 LCOOP). ${ }^{4}$

\footnotetext{
${ }^{4}$ Principios cooperativos de la ACI de 1995: 1. Adhesión voluntaria y abierta. 2. Gestión democrática por parte de los asociados. 3Participación económica de los asociados. 4. Autonomía e independencia. 5. Educación, formación e información.6.Cooperación entre cooperativas. 7. Interés por la comunidad.
}

REVESCO N 111 - Segundo Cuatrimestre 2013 - ISSN: 1885-8031 - www.ucm.es/info/revesco 
Es obligado que el socio público acomode también su actuación a los principios cooperativos y, sin ánimo de exhaustividad, podemos decir que, por ejemplo, el cumplimiento del principio de adhesión voluntaria y abierta (primer principio cooperativo ACI), recogido como libre adhesión y baja voluntaria en el artículo 1 LCOOP queda condicionado a que se le autorice al socio público mediante el correspondiente procedimiento administrativo, tanto para darse de alta como de baja en la sociedad cooperativa. Por tanto el ejercicio de este derecho o principio tampoco reside en el socio público por si mismo sino en instancias superiores. Al igual que un expediente técnico de administración forma la voluntad de constituir del socio público, será necesario, también, un expediente técnico de administración el que autorice el alta o baja de la sociedad cooperativa del socio público. Por lo que esa libertad reside en el ente autorizante más que en el autorizado. No obstante, no podemos ver esto como una alteración del régimen jurídico de la sociedad cooperativa sino cómo una peculiaridad del socio debido a su naturaleza pública.

Igualmente el socio público tendrá que acomodar su actuación al respeto democrático, otro principio cooperativo, lo que es ajeno a su propia naturaleza pública que tiende a controlar por el capital u otros medios las sociedades en las que participa. Ello será posible si se conjugan las exigencias del socio público con una estructura organizativa más cercana a una empresa mercantil que a una mutua, lo que no será difícil dado el entorno económico actual y la permisividad legal en este sentido.

Por tanto, la presencia del socio público puede suponer en algunos casos una alteración de las notas esenciales de las cooperativas, cuyo comportamiento puede ser atípico con respecto a la estructura utilizada, pero que, sin embargo, el ordenamiento tutela y es, en consecuencia, perfectamente válida para la finalidad propuesta. En estos casos, el ordenamiento protege más la finalidad perseguida con esa estructura organizativa que el sustrato de la misma. En esta posible disociación entre esencia y forma, el ordenamiento se inclina más por la naturaleza del interés perseguido que, como elemento causal que articula la estructura organizativa, es merecedor de tutela (Lacruz 1999: p. 196).

No obstante, los posibles matices que pueda introducir la presencia del socio público respecto a su cumplimiento de los principios cooperativos no altera, a nuestro entender, el régimen jurídico que rige a las sociedades cooperativas. 
b. El socio público y las distintas clases de cooperativas: especial referencia a las que cumplen con una función social, a las que prestan servicios públicos y a las mixtas.

La segunda cuestión que nos planteábamos era si esa misma naturaleza le permite participar como socio en cualquier clase de cooperativas y acomodar los fines públicos a los privados o por el contrario la exclusión podría venir por vías distintas a las legales.

Desde el punto de vista fundacional, el objeto social se ubica dentro del esquema contractual como un elemento causal que alude al ramo de actividad que de forma permanente se propone realizar la sociedad como único medio de alcanzar el fin propuesto. Las sociedades cooperativas permiten una mejor adecuación entre estructura organizativa, actividad empresarial-objeto social y fin propuesto dado que las propias leyes de cooperativas recogen las distintas clases de cooperativas que tendrán que estar en consonancia con la actividad empresarial y los fines perseguidos.

No obstante, cualquiera que sea su objeto social, el elemento conceptual cooperativo exige necesariamente que éstas estén orientadas a satisfacer las necesidades de sus asociados y, por tanto, también la del socio público. Debido a ello, la idoneidad de la participación de un ente público como socio en una determinada cooperativa dependerá, de una parte, del objeto social de esta, y, de otra parte, de la forma de participar en la misma, puesto que las propias leyes cooperativas prevén distintas clases de socios.

Así, por ejemplo, en cuanto al objeto social, nada impide a un ente público intervenir como socio en una sociedad cooperativa de viviendas o locales, para proveerse a sí mismo de los espacios físicos donde desarrollar su actividad, a la vez que ayuda a sus ciudadanossocios cooperativos a satisfacer sus necesidades cooperativas. En estos casos estaríamos hablando de un socio común. Pero tampoco es inconveniente que solo fuera un socio inversor aportando, por ejemplo, los terrenos, ayudando de esta forma al desarrollo del objeto social y consiguiendo el fin social propuesto, como es que sus ciudadanos-socios obtengan las viviendas que necesitan, sin él intervenir en el desarrollo diario de la actividad cooperativizada propiamente dicha.

El desarrollo legal de los distintos tipos de sociedades cooperativas recogidas en la LCoOP deja entrever de qué forma puede participar el socio público, si como asociado común, 
colaborador, etc. En el ejemplo antedicho, sociedades cooperativas de vivienda, se recoge expresamente esta posibilidad, mientras que en otras como las sociedades cooperativas agrarias no parece posible que un ente público participe directamente como un socio común, dada la exigencia del objeto social pero sí de forma indirecta a través de otras sociedades mercantiles. "También podrán formar parte como socios de pleno derecho de estas cooperativas, (agrarias) las sociedades agrarias de transformación, las comunidades de regantes, las comunidades de aguas, las comunidades de bienes y las sociedades civiles y mercantiles que tengan el mismo objeto social o actividad complementaria y se encuentre comprendido en el primer párrafo de este artículo..." (art. 93.1 LCOOP). Por tanto, la forma en que el socio público puede participar en la sociedad cooperativa puede ser diversa en función de las posibilidades que le otorga la ley, y en aquéllas donde no tenga cabida como socio común, lo podrá hacer como un socio colaborador o inversor. Algunas leyes cuando se refieren a estas clases de socio parece que están pensando en el socio público. Pues en definitiva ninguna quiere desaprovechar la ventaja o el plus añadido que puede aportar una administración pública como socio. Aunque en la práctica, no parece que sea la forma societaria más utilizada por las Administraciones públicas para intervenir en la economía, ni la más demandada por los socios privados para colaborar con el sector público.

Si bien el socio público puede participar directa o indirectamente en cualquier sociedad cooperativa cualquiera que sea su objeto social, a los efectos que aquí nos interesa hay que hacer especial referencia a tres clases de cooperativas de muy distinta naturaleza y por distintos motivos que se expondrán a continuación. Éstas son, las que cumplen una función social, las que prestan servicios públicos y las denominadas por la ley como mixtas.

Las primeras, encaminadas a cumplir una función social, acogen distintas figuras dispersas por el articulado de las diferentes leyes de cooperativas pero todas tienen un denominador común, la idoneidad de la participación del socio público en las mismas, debido a la labor social hacia la que está orientado su objeto social. Dentro de este grupo se ubican las previstas en la Disposición Adicional primera de la LCOOP que serán aquellas que “....gestionen servicios de interés colectivo o de titularidad pública, así como las que realizan actividades económicas que conduzcan a la integración laboral de personas que sufran cualquier clase de exclusión social..." ${ }^{5}$ En estos casos, no es estrictamente necesario,

\footnotetext{
${ }^{5}$ En el mismo sentido se expresa el artículo 132 de la Ley 8/2006, de 16 de noviembre de sociedades cooperativas de la región de Murcia. (LCRM)
}

REVESCO No 111 - Segundo Cuatrimestre 2013 - ISSN: 1885-8031 - www.ucm.es/info/revesco 
pero sí lógico, la presencia del socio público ya que el servicio es de interés colectivo o general o la titularidad del servicio es público $\mathrm{y}$, por tanto, de provisión pública de acuerdo con nuestro actual modelo constitucional que, junto a esta estructura organizativa típica de intervención directa en la economía, indican la idoneidad de que en este tipo de sociedades participe un ente público como socio. La misma disposición adicional a que nos venimos refiriendo recoge los rasgos estatutarios que como mínimo deben cumplir estas sociedades cooperativas, aunque no nos dice cuales serían la ventajas específicas respecto de otras clases de sociedades cooperativas con igual o parecido objeto social que no cumplieran con estas exigencias.

Dentro de este mismo grupo, y si cabe con mayor razón, hay que introducir las sociedades cooperativas de iniciativa social que prestan servicios asistenciales (sanitarios, educativos, culturales, etc.,) o servicios de integración laboral de sus asociados que sufran exclusión social o busquen la satisfacción de necesidades sociales no atendidas por el mercado (art. 106.1 LCOOP. o art. 130 LCRM). Recogiendo expresamente que las entidades y organismos públicos podrán participar en calidad de socio en la forma estatutariamente establecida (art. 106.2 LCOOP), esta aparente libertad contractual queda condicionada, a continuación, porque se remite para la regulación de la cooperativa de iniciativa social a las normas relativas a la clase de cooperativa a que pertenezca (art. 106.3 LCOOP). A simple vista parece una contradicción, pues muchas clases de cooperativas establecen los límites en los que deben moverse los socios, sean estos públicos o privados. No obstante, en nuestra opinión, el legislador hace expresa mención de ello con la intención de liberar al socio público de esa atadura de régimen en esta clase de cooperativas, aunque, en todo lo demás si deberán seguir lo preceptuado para el tipo de cooperativa elegido por la de iniciativa social. Hacer otra interpretación dejaría vacío de contenido y sin sentido el punto tercero del artículo 106 LCOOP.

Por ultimo, dentro de este grupo hay que tomar en consideración a las sociedades cooperativas de interés social (art. 94 LCAND) ${ }^{6}$ o integración social (art.98 LCCV entre otras leyes cooperativas comunitarias). ${ }^{7}$ Independientemente de sus rúbricas, estas tienen por objeto

\footnotetext{
${ }^{6}$ Ley 14/2011, de 23 de diciembre, de Sociedades Cooperativas Andaluzas. (LCAND).

${ }^{7}$ Art. 98 de la Ley 8/2003, de 24 de marzo, de Cooperativas de la Comunidad Valenciana (LCCV); art. 127 de la Ley 4/1993, de 24 de junio, de Cooperativas del País Vasco, (LCPV); art. 125 de la Ley 5/1998, de Cooperativas de Galicia, modificada por la Ley 14/2011, de 16 de diciembre, (LCG); art. 121 de la Ley 20/2002, de 14 de noviembre de Cooperativas de Castilla-la Mancha (LCCM).
}

REVESCO No 111 - Segundo Cuatrimestre 2013 - ISSN: 1885-8031 - www.ucm.es/info/revesco 
la integración socio-laboral de colectivos en situación de dependencia (discapacitados, menores, ancianos, inmigrantes, etc.). En estas “cooperativas de integración social podrá participar como socio una entidad pública responsable de la prestación de servicios sociales, mediante la designación de un delegado del poder público. Este delegado prestará su trabajo personal de asistencia técnica, profesional y social junto a los socios de la cooperativa y asistirá a las reuniones de los órganos sociales, ejercitando los derechos de socio.” (art. 98.2 LCCV).

Este apartado tiene dos lecturas. Una, de forma explícita se nos da la información de quién es socio público, servicios sociales, y dos, la persona autorizada para participar en la sociedad por delegación de aquél como autorizado, necesariamente deber reunir una serie de condiciones que permita una asistencia técnica, profesional, social, ejercitando los derechos de socio.

Por lo expuesto hasta aquí, se desprende que la finalidad propuesta por este grupo de sociedades cooperativas está normalmente alejada del interés del mercado "strictus sensu" por lo que son genuinamente de interés público y, por tanto, idóneas para una colaboración público-privada, a fin de aunar esfuerzos y conseguir subsanar las fallas del mercado.

Este tipo de cooperativas son consideradas como un tipo hibrido que toma rasgos distintivos de las asociaciones y de las sociedades mercantiles, consideradas como de economía solidaria, que es un subsector de la economía social (Vargas, 2007: p. 93-133). Éstas parecen ser el "hábitat natural" de la Administración pública dado que las finalidades perseguidas por las mismas son, insistimos, objeto de provisión pública, al quedar normalmente desatendidas por los mercados, por lo que la combinación público-privado puede ser lógica para subsanar las carencias o inconvenientes de cada sector. O dicho de otro modo, para que la sociedad cooperativa pueda beneficiarse del "plus" que puede aportar el socio público, y éste subsanar o completar sus carencias en cuanto a flexibilidad de la gestión, rapidez, cercanía, eficiencia, etc. No obstante, en nuestra opinión, si en ella participa un socio público no deberían quedar encuadradas dentro de la economía solidaria. El objeto social es de provisión público, uno o varios socios también son públicos, por lo que no obedecería más que a la posibilidad que tiene la Administración de intervenir en economía a través de cualquier organización jurídica pública o privada prevista en nuestro Ordenamiento jurídico para conseguir su fines de interés general o de interés público, por lo que no se le debería 
aplicar la etiqueta de solidario al capital público que si puede acompañar capital privado exclusivamente. El capital privado si puede ser solidario, el público debe tender a subsanar las deficiencias del mercado, no de forma voluntaria como aquél, sino por obligación constitucional (art. 128.2 CE).

En la misma línea, pero con una finalidad distinta, está el segundo grupo, al que nos referíamos anteriormente, las sociedades cooperativas de servicios públicos. Sólo algunas leyes cooperativas autonómicas recogen a estas cooperativas como una categoría distinta y separada de las demás, no así en la norma estatal que es precisamente la que hemos tomado de modelo, pero el objeto del presente estudio, impide pasarlas por alto. Este tipo de sociedades cooperativas son también campo abonado de participación pública debido a su objeto social. No obstante, las leyes que se refieren a estas específicas cooperativas son parcas en su reglamentación, aunque, cabe destacar lo dispuesto para ellas en el artículo 99 LCCV:

“1. La Generalitat Valenciana y las corporaciones locales obligadas a asegurar la existencia de servicios públicos podrán proveer que la prestación directa de éstos se haga mediante la constitución de cooperativas de servicios públicos.

2. En estas cooperativas participarán como socios la entidad o entidades públicas promotoras y los usuarios de los servicios que sean objeto de la cooperativa, sin perjuicio del control público que aquéllas se reserven en cuanto a las condiciones de prestación de los servicios públicos.

3. Se excluye, en todo caso, la prestación de servicios públicos que exijan ejercicio de autoridad pública, como los de orden público y protección civil.”

Este artículo puede servirnos de modelo para establecer el patrón de estas clases de sociedades cualquiera que sea la Administración pública, territorial o institucional que participe. Así el socio público necesariamente será el encargado de proveer el servicio público (Sosa, 2008; Ariño, 1997; Villar, 1993;) que, junto a los usuarios del servicio, se prestará directamente mediante este tipo de sociedades. Con una particularidad, que en mi opinión, las aleja del régimen ordinario de las cooperativas y las acerca a las típicas empresas públicas, la posibilidad que tiene el ente público de reservarse el control público de las condiciones de prestación del servicio, así como la exclusión de aquéllos servicios públicos que supongan 
ejercicio de autoridad por estar fuera de las posibilidades de ejercerse a través de estructuras jurídicas privadas, (Disposición adicional duodécima de la LOFAGE).

La tercera clase de sociedades cooperativas a las que hacíamos referencia era las denominadas por la ley como mixtas. Estas sociedades cooperativas se caracterizan porque en ellas se conjugan elementos de las sociedades de capital y de las de economía social. Inclinándose hacia las primeras, por cuanto permite la existencia de socios cuyo derecho de voto se determina en función del capital aportado, representado por medio de títulos o anotaciones en cuenta que, se denominaran partes sociales con voto, sometidas a la legislación del mercado de valores y supletoriamente por la legislación de sociedades anónimas para las acciones (art.107. 1,3). ${ }^{8}$ En este tipo de sociedades cooperativas las Administraciones públicas pueden sentirse más cómodas por cuanto tienen una rancia tradición de tratar con acciones sociales de las distintas empresas públicas e incluso las normas administrativas regulan el régimen jurídico de adquisición y transmisión de las acciones o participaciones sociales, su tratamiento contable, cómo y dónde deben quedar depositadas, etc. Este mismo tratamiento recibirían las partes sociales de las sociedades cooperativas mixtas.

c. Clase de socio cooperativo que más se ajusta a la naturaleza pública del socio en las sociedades cooperativas de participación pública.

Por último, la tercera cuestión que nos planteábamos al inicio del epígrafe era qué clase de socio de las previstas en la ley se acomoda más a la naturaleza pública del socio. Todas las leyes de cooperativas recogen las mismas o muy parecidas clases de socios, aunque con diferentes matices y denominaciones. Sin entrar al detalle en ellos, podemos distinguir al socio común, socio colaborador, de trabajo, socios inactivos, socios asociados, etc. La elección del socio público de participar de una forma u otra en una sociedad cooperativa dependerá, como ya hemos dicho, del objeto social concreto de la cooperativa y de como éste quiera o pueda alcanzar los fines propuestos. No cabe duda que por la naturaleza pública del socio este se acomodará mejor a una clase de socio que otras, pero nada impide que si el objeto social lo permite, el socio público participe en la actividad cooperativizada propia del objeto social de la cooperativa como cualquier otro socio común.

\footnotetext{
${ }^{8}$ La ley de sociedades anónimas ha sido derogada y este tipo societario está regulado por el Real Decreo Ley 1/ 2010, de 2 de julio, por el que se aprueba el Texto Refundido de la Ley de sociedades de capital.
} 
No obstante, desde la posición administrativa del ente, consideramos que la clase de socio que mejor se acomodaría a esa naturaleza pública del socio, es la de socio colaborador. Definida en la ley como aquél que sin poder desarrollar o participar en la actividad cooperativizada propia del objeto social de la cooperativa, puede contribuir a su consecución (art. 14 LCOOP). Salvo en sociedades cooperativas consideradas como de economía mixta, ni en las de servicios públicos (Sosa, 2004: p. 332; Santiago, 2010: p.105). A pesar de que este artículo sólo hace referencia a la aportación de capital como forma de colaborar, teniendo seguramente el legislador en mientes la figura del socio capitalista. Es posible que esa colaboración no tenga porqué circunscribirse solo y exclusivamente a una aportación de capital, sino que, además puede haber también otras formas de colaboración como aportar su experiencia, contactos, facilitar trámites, información, etc., todo ello como socio, no como Administración. Es decir, esa colaboración la haría desde dentro de la estructura societaria poniendo al servicio de ésta los recursos de que dispone el socio público. Por supuesto sin transgredir, como Administración pública, los principios bajo los que tiene que actuar para con cualquier administrado, principalmente, el de objetividad; transparencia; cooperación y no discriminación con otras figuras afines, pero de las que no sea socio el ente público.

Esta clase de socio tiene la ventaja de que no tiene que desarrollar actividades cooperativizadas en el seno de la sociedad, no se le pueden exigir nuevas aportaciones al capital social, (no olvidemos que las aportaciones son de capital público y por tanto, de todos los ciudadanos, capital que solo es gestionado por el ente público pero no es su propietario).

Tiene la desventaja de que las aportaciones de capital no pueden exceder del cuarenta y cinco por ciento del total de las aportaciones al capital social, ni el conjunto de votos a ellos correspondiente, sumados entre sí, podrá superar el treinta por ciento de los votos en los órganos sociales de la cooperativa. Esta cautela legislativa puede ser fácilmente superada si hubiera más de un socio público y entre todos sumaran la mayoría del capital. El control sería público lo que puede contradecir el espíritu del régimen jurídico de la cooperativa, si no coincidieran los intereses del socio público y los de los socios privados.

Podemos apuntar también como posible desventaja, si se diera el caso, la inseguridad jurídica que puede acarrear el que sea la Asamblea General la que fije los criterios de ponderada participación de estos socios en los derechos y obligaciones socioeconómicos de la cooperativa. En cooperativas con un gran número de socios privados es posible que el socio 
público quede en desventaja, con respecto al resto de socios comunes si modifican en demasía el contenido de los estatutos sociales en ese sentido de cambio de atribuir unas veces unos derechos, otras veces otros, lo que podría obviarse introduciendo clausulas estatutarias que establezcan cuándo y cómo y porqué se podría modificar esos derechos.

\section{PARTICULARIDADES DE LA APORTACIÓN SOCIAL DEL SOCIO PÚBLICO A UNA SOCIEDAD COOPERATIVA}

En las sociedades cooperativas el capital social también se forma con las aportaciones de los socios (art. 45 LCOOP). No obstante, en este tipo de sociedades el capital social no cumple con las mismas funciones que en una sociedad de capital. Mientras que en estas últimas la sociedad se estructura en torno al capital, en las sociedades cooperativas su importancia dependerá de la clase de cooperativa, pues la organización se estructura más en torno a la actividad cooperativizada de los socios que a la aportación de capital que éstos realicen. Ello, a pesar de que la sociedad no puede constituirse sin un capital mínimo que tiene que estar totalmente desembolsado desde la constitución de la misma. Lo que demuestra la preocupación legislativa de que la sociedad cuente con un capital mínimo que le permita hacer frente a sus obligaciones sociales desde el inicio de la actividad empresarial de que se trate más que servir para medir el grado de poder que cada socio tenga en la sociedad, dada la limitación legal en la participación en el capital social a la que haremos referencia posteriormente. A los efectos que aquí nos interesa, debemos analizar qué puede aportar el socio público y cómo debe aportarlo.

a. Las clases de aportación al capital social.

La aportación de capital en la sociedad cooperativa es principalmente dineraria. No obstante, si lo prevén los Estatutos y lo acordase la Asamblea General, podrá ser también no dineraria pero siempre susceptible de valoración económica (art. 45 LCOOP). Esto es importante en el caso de sociedades cooperativas de participación de capital público porque, precisamente, en muchas ocasiones la cooperativa se articulará en torno a la aportación no dineraria del socio público (concesiones, arrendamientos, disfrute de bienes muebles e inmuebles, etc.).

REVESCO No 111 - Segundo Cuatrimestre 2013 - ISSN: 1885-8031 - www.ucm.es/info/revesco 
Como en cualquier tipo societario la aportación dineraria es la más simple, transparente y cómoda, dado que solamente tendrá que constar la cuantía en el expediente técnico de autorización de constitución de la sociedad.

Siendo los estatutos sociales los que fijen la forma de acreditar las aportaciones al capital social de cada uno de los socios.

Tratándose de aportaciones no dinerarias, éstas podrán consistir en bienes o derechos susceptibles de valoración económica, siendo el Consejo Rector el encargado de fijar su valoración, previo informe de uno o varios expertos independientes, designados por dicho Consejo. El informe debe contener las características del bien, el valor que el experto ha asignado a la aportación y los criterios utilizados para calcularlo (art. 45.4 LCOOP).

Las aportaciones no dinerarias o «in natura» efectuadas por el socio público requieren de un complejo proceso administrativo previo a la aportación al negocio fundacional, dependiendo de la naturaleza jurídica del bien a aportar.

Los bienes de cualquier Administración pública, también las autonómicas y locales, se ordenan en bienes de dominio público y de dominio privado. Los primeros a su vez pueden ser bienes demaniales por naturaleza o bienes demaniales afectos a un fin $y$ son bienes inalienables, imprescriptibles e inembargables y, por tanto, fuera del tráfico jurídico privado mientras mantengan esa consideración que solo pueden perder mediante un expediente administrativo de desafectación. Los bienes privativos o de dominio privado sí son alienables y prescriptibles pero inembargables mientras estén en poder de la Administración, aunque sí son objeto de tráfico jurídico y, por tanto, pueden ser aportados para formar el capital de una sociedad mercantil. ${ }^{9}$

En consecuencia, la aportación «in natura» necesariamente debe cumplir dos requisitos inexcusables. De una parte, debe ser siempre de valoración económica, (lo que se exige para cualquier aportación, no solo pública, como ya hemos mencionado). Aunque en muchas de las clases de las sociedades cooperativas el capital social no cumpla exactamente con las mismas funciones que en una sociedad de capital, en cuanto a servir a las exigencias

\footnotetext{
${ }^{9}$ Vid. Art. 69 LPAP se expresa en los siguientes términos: «Los bienes y derechos demaniales perderán esta condición, adquiriendo la de patrimoniales, en los casos en que se produzca su desafectación, por dejar de destinarse al uso general o al servicio público. 2. Salvo en los supuestos en esta ley, la desafectación deberá realizarse siempre de forma expresa»; En parecidos términos se expresa la Ley 7/1985, 2 abril, de base de régimen local; Igualmente las normas que regulan a las CCAA que no pueden contradecir la estatal.
} 
jurídico privadas de determinación del capital social, así como para establecer la relación económica entre éste y el patrimonio de la sociedad y, por ultimo, para cumplir con la función esencial de garantía de acreedores de la sociedad, que se frustraría al no poder éstos valorar esos bienes integrantes de dicho patrimonio para la satisfacción de sus créditos. Las aportaciones «in natura» deben de poder ser valoradas económicamente por una razón de orden jurídico de tráfico mercantil como manda la ley.

De otra parte, deben de poder ser objeto de tráfico jurídico privado pues sí no podría dar lugar a un negocio jurídico de fundación con objeto ilícito y estaríamos ante una causa de nulidad, lo que imposibilitaría su inscripción registral (arts. 1.272 y 1.666 CC).

Para obviar este problema el bien debe someterse a un procedimiento jurídico administrativo que lo declare apto para ser aportado y le haga perder su afectación al fin público al que estaba destinado. Este procedimiento necesariamente tiene que ser previo al acto material de aportación. Sólo entonces el bien estará en disposición de someterse al procedimiento jurídico privado que supone el negocio fundacional de sociedad. De no procederse así habría una mutación de destino del bien pero no un cambio de régimen jurídico, lo que supondría la nulidad absoluta del negocio de aportación por falta de objeto aportado al negocio (art. 1.261.2 CC). No olvidemos que el capital social que inicialmente puede formar el patrimonio de la sociedad sirve también para proteger los derechos de los terceros y de los demás socios cooperativos. Si estos bienes aportados son indisponibles no cumplen con la función que la ley les encomienda.

En orden a cumplir con estas exigencias requieren especial atención las aportaciones de bienes demaniales por naturaleza, ${ }^{10}$ que no pueden cambiar de destino, la desafectación y posterior aportación del bien a una sociedad cooperativa podría suponer un cambio de titularidad y de régimen jurídico (de público a privado) pero no de destino. Estas aportaciones son de difícil valoración económica, ni tampoco pueden cumplir con la función que se les demanda de garantía de acreedores sociales, e igualmente estos bienes quedan excluidos del patrimonio resultante de la liquidación si llegara el caso, al no poder disponerse de los mismos (García, 2006: p.129). De haber estas aportaciones, exigirían clausulas estatutarias específicas que sortearan las dificultades expuestas y que permitieran cumplir la función de

\footnotetext{
${ }^{10}$ Por ejemplo, las aguas, presas, canales, ríos, carreteras, caminos, parques naturales o forestales, etc. Difícilmente se pueden dedicar a otro fin, algunos podrán ser abandonados en su uso pero no dedicarlos a otra cosa.
}

REVESCO No 111 - Segundo Cuatrimestre 2013 - ISSN: 1885-8031 - www.ucm.es/info/revesco 
concreción del capital aportado y la función de garantía de acreedores, para evitar que se desplace hacia la Administración aportante la responsabilidad de las posibles futuras deudas sociales. De esta forma, se evitaría que la sociedad cooperativa se convirtiera en un puro instrumento al servicio de la actividad, imponiéndose la dimensión de la aportación pública sobre las privadas como eje fundamental de explotación de la actividad cooperativizada y que tantos problemas ha dado en el marco de las sociedades anónimas instrumentales. Sobre todo, porque en una sociedad cooperativizada no se puede hablar de interés general, salvo que fuera una sociedad cooperativa de servicios públicos.

Por último, la aportación de los bienes patrimoniales precisa la previa declaración de alienabilidad y un expediente de enajenación (art. 132 LPAP) para poder ser aportados en virtud de cualquier negocio jurídico traslativo, típico o atípico (art. 132 LPAP), a fin de hacer compatible la enajenación con las exigencias fundacionales de la sociedad cooperativa. Solventados estos impedimentos jurídicos, la naturaleza de los bienes en nada condiciona su aportación, es más su patrimonialidad los hace idóneos para ser objeto de aportación.

b. El título de la aportación.

Una dificultad añadida en este tipo de sociedades cooperativas es que su régimen jurídico no prevé la posibilidad de que la aportación pueda ser a título distinto del de propiedad como ocurre en el caso de las sociedades de capital. En las sociedades cooperativas "las aportaciones no dinerarias no producen cesión o traspaso ni aun a los efectos de la Ley de Arrendamientos Urbanos o Rústicos, sino que la sociedad cooperativa es continuadora en la titularidad del bien o derecho. Lo mismo se entenderá respecto a nombres comerciales, marcas, patentes y cualesquiera otros títulos y derechos que constituyan aportaciones de capital "(art.45.5 LCOOP). Para el caso en que no se pueda o no se quiera perder la titularidad pública del bien, y dado que no se puede aportar a título distinto del de propiedad, habrá de tenerse muy en cuenta un tipo de aportación que puede venir a resolver este problema, tal cómo es la concesión administrativa como fórmula que permite a la Administración que sujetos privados exploten bienes de dominio público, o presten servicio públicos corriendo con los riesgos económicos de la empresa. Ello permite obviar el problema que se le presenta a cualquier Administración pública con bienes demaniales no desafectados, ya que en estos casos hay que distinguir entre los bienes afectos al uso o servicio público, o patrimoniales de titularidad pública y el derecho en que consiste la concesión. Lo que se 
aporta es el derecho de explotación y no los bienes o la actividad objeto de ese derecho. La concesión administrativa es el objeto de aportación y es perfectamente valorable económicamente y transmisible en el tráfico mercantil, siempre que ésta no requiera especiales características en el concesionario, ya que ello condicionaría la conclusión del contrato de aportación e impediría la libre transmisión de la misma.

c. Los límites cuantitativos de la aportación al capital social.

En este tipo de sociedades el status jurídico político y económico del socio no viene determinado por la aportación al capital como en las sociedades de capital, por cuanto legalmente las aportaciones de cada socio no podrán exceder de un tercio del capital social (art. 45. 6 LCOOP). Por tanto, la configuración del status de socio dependerá más del tipo de socio que de la aportación. Debido a que legalmente se permite que los estatutos sociales rompan el principio de igualdad sobre el que se erige la sociedad cooperativa y otorguen derechos de contenido distintos dependiendo del tipo de socio. El patrón seguido por todas las leyes cooperativas tiende a beneficiar la posición política del socio en función a la aportación del mismo, aunque estableciendo límites máximos de participación para no correr el riesgo de que estatutariamente se ignorasen los principios cooperativos. No es otro el objeto del voto plural ponderado, en proporción al volumen de la actividad cooperativizada para los socios que sean entidades públicas, que permite disponer de más de un voto a las entidades públicas (art. 26 LCOOP). Esta posibilidad no está prevista sólo para el socio público, pero parece hecha a la medida del socio público, por cuanto le va a permitir una proporcionalidad entre lo aportado y lo recibido, aunque no pueda superar los cinco votos sociales. En la mayoría de los casos le va a permitir una ventaja respecto del resto de socios en el diseño de la política societaria.

Igualmente el socio público puede llegar a una posición privilegiada dentro de la sociedad cooperativa cuando ésta sea considerada como mixta (art. 107 LCOOP). En las que la posición de socio se configura como si de un socio capitalista se tratara debido a que el derecho de voto en la Asamblea General se podrá determinar, de modo exclusivo o preferente en función del capital aportado, sin tener en cuenta la participación en la actividad cooperativizada. Los títulos en que se represente el capital se denominan partes sociales con voto y podrán ser representados por medio de títulos o anotaciones en cuenta, sometidos a la legislación reguladora del mercado de valores. También en estos casos se establecen límites 
cuantitativos en relación al porcentaje de votos que respecto al total tienen estos especiales socios, a fin de que el control de la sociedad cooperativa siga en manos de los socios ordinarios. Esto parece más una buena intención que una realidad, pues la ventaja de estos socios es evidente respecto a los demás, debido a que el resto de socios tendrán mayores dificultades para tomar acuerdos en contra de lo perseguido por los socios titulares de partes sociales con voto.

Si nos fijamos en la participación de la Administración pública en otros tipos de sociedades mercantiles y los fines perseguidos en las mismas, tendremos que concluir que esta es la forma óptima de preservar el equilibrio que exige comportarse como un socio privado sin alterar en demasía el régimen jurídico del tipo societario y no perjudicar el interés general al que se debe como Administración. Es más, las normas administrativas generales consideran a estos títulos integrantes del patrimonio empresarial de la Administración General del Estado o de sus organismos públicos y, por tanto, sometido a lo dispuesto en el Título VII de la LPAP, ya que estos títulos estarían incluidos en el grupo de aquellos que son "susceptibles de ser negociados en mercados secundarios organizados que sean representativos de derechos para la administración General del Estados o sus organismos públicos, aunque su emisor no esté incluido entre las personas jurídicas enunciadas en el apartado 1 del presente artículo" (art. 166.3 LPAP). Las personas jurídicas a las que se refiere el artículo son las entidades públicas empresariales, sociedades mercantiles estatales y sociedades mercantiles no estatales pero que se encuentren en algún supuesto previsto en el artículo 4 de la Ley 24/1998, de 28 de julio del Mercado de valores respecto de la Administración General del Estado o de sus organismos públicos. ${ }^{11}$ No cabe duda que en estos casos particularmente planea la sombra de la naturaleza pública del socio que habrá de respetar lo dispuesto en las normas administrativas generales que le son de aplicación.

\section{CONCLUSIONES}

Las sociedades cooperativas de participación pública están previstas legislativamente pero carecen de una regulación específica que acoja las posibles peculiaridades de régimen jurídico que lleva aparejada la naturaleza pública de uno de sus socios, el público.

\footnotetext{
${ }^{11}$ Hay que recordar que son sociedades mercantiles estatales aquellas en que el socio público tiene mayoría del capital de forma directa o indirecta. Mientras que en último grupo expuesto no tiene mayoría de capital pero controla a la sociedad por alguno de los medios previstos en ese artículo 4
}

REVESCO No 111 - Segundo Cuatrimestre 2013 - ISSN: 1885-8031 - www.ucm.es/info/revesco 
Las Administraciones Publicas, ya sean estatales, autonómicas o locales, pueden intervenir en la economía a través de las sociedades cooperativas cualquiera que sea su clase, dando lugar a un tipo de sociedad cooperativa en donde convive el capital público y el capital privado, forma jurídica idónea para la consecución de fines propios de la acción pública.

La peculiaridad de este tipo de socio público exige tener en consideración tanto la legislación pública que le sea de aplicación al ente público como futuro socio como las que le sean de aplicación a la organización jurídico privada en la que participa si caen en el supuesto de hecho de las mimas. A pesar de que estas normas públicas, estatales o autonómicas regulan solo algunos aspectos de régimen jurídico de las sociedades mercantiles en mano pública, sin especificar tipos. Para, a reglón seguido, establecer solo reglas para las acciones u otros títulos negociables. Esto no debe llevarnos a engaño y considerar que solo están previstas esas normas para las sociedades anónimas. A las sociedades cooperativas le serán de aplicación todas aquéllas que se refieran a sociedades mercantiles.

Solo las normas que regulan a los entes locales se refieren de forma específica a las sociedades cooperativas como una forma jurídica más de participación indirecta en la economía pero sin preceptos que establezcan un régimen jurídico propio.

Tampoco las distintas leyes de cooperativas recogen referencias significativas en orden a regular esta posibilidad, limitándose a reconocer que socio puede ser un ente público y poco más.

En este tipo de sociedades cooperativas de participación pública, ya sea estatal o autonómica no podemos confundir el negocio jurídico fundacional de la sociedad con la formación de la voluntad de constituir del socio público, que se forma mediante un procedimiento administrativo que se concreta en un expediente técnico de autorización, donde consta no sólo la autorización para constituir un determinado tipo social, sino que se recogen, asimismo, otros elementos definidores propios de la estructura organizativa tan importantes como, por ejemplo, la aportación al capital. Ese expediente técnico de autorización equivale al consentimiento del socio privado. Elemento esencial de cualquier contrato, también de éste, que debe adjuntarse a la escritura pública de constitución. Esto se debe a la naturaleza pública del socio que necesariamente está sometido en su actuación pública y privada al principio de legalidad.

REVESCO No 111 - Segundo Cuatrimestre 2013 - ISSN: 1885-8031 - www.ucm.es/info/revesco 
Hay que tener en cuenta igualmente que, si bien el régimen jurídico privado de las sociedades cooperativas no admite que éstas sean de capital únicamente público o mayoritariamente público, podría darse el caso que la presencia de varios socios públicos en una misma cooperativa diera lugar a que tuvieran la mayoría del capital social. En estos casos la cooperativa quedaría integrada en el sector público y sometida a las normas administrativas que le son de aplicación. Además, en estos casos, la denominación social de la cooperativa podría hacer referencia a estas circunstancias al quedar exenta de la prohibición establecida en el artículo 405.2 del Reglamento del Registro Mercantil.

Especial atención debe tener también, en el proceso de fundación de este tipo de sociedades cooperativas, el periodo de constitución debido a que la aportación al capital social de la cooperativa proviene de fondos públicos sometidos a finalidad. Por eso es conveniente que el expediente técnico de autorización prevea y distinga entre los dos actos formales de que se compone el proceso fundacional y su diferencia temporal entre el otorgamiento de la escritura pública y la inscripción registral. Esto permitiría disponer de esos fondos públicos aunque no se haya realizado el acto de inscripción que es para lo que se autorizaron. Si, además, el expediente técnico de autorización contiene también las facultades específicas que otorga en este periodo de constitución y a quien se las otorga, evitará una alteración en el régimen de responsabilidad entre los socios públicos y privados.

No hay inconveniente legal para que el ente público pueda ser socio de cualquier clase de cooperativas, por cuanto los posibles matices que pueden darse en orden al cumplimiento de los principios cooperativos no alteran los cimientos del régimen jurídico cooperativo pero, quizás, su hábitat natural esté en tres grupos, las que cumplen con una función social, las que prestan servicios públicos y las mixtas. Ello por razones opuestas, las dos primeras porque la provisión de su objeto social suele ser de obligación pública y las mixtas porque el estatus de socio se acerca a un régimen más capitalista, lo que permite al socio público comportarse de forma afín a como lo hace en otras sociedades de capital cuya regulación está prevista en las leyes administrativas públicas.

En cuanto a la forma de desarrollar la actividad cooperativizada, las propias leyes de cooperativas dan la oportunidad de que si el objeto social no es compatible con la naturaleza pública del socio, éste pueda hacerlo como un socio colaborador que permite coadyuvar a la 
consecución del objeto social propuesto sin necesidad de intervenir como socio común en el desarrollo diario de la actividad cooperativizada.

Por ultimo, la aportación al capital social, requisito esencial del negocio fundacional, requiere de un complejo proceso administrativo previo al negocio fundacional, dependiendo de la naturaleza jurídica del bien o derecho a aportar.

Si la aportación es dineraria, aun siendo la más simple y sencilla, necesitará de la previa autorización para disponer de los fondos de que se trate.

Si la aportación es no dineraria o «in natura» esta tiene que poder ser valorable económicamente y poder ser objeto de tráfico mercantil. De ahí, que si se trata de bienes de dominio público tienen que ser sometidos a un expediente administrativo de desafectación, previo al negocio fundacional, para que pierdan el carácter de inalienables, imprescriptibles e inembargables y puedan ser objeto de tráfico privado. Mientras que los bienes privativos o de dominio privado sí son alienables y prescriptibles pero inembargables mientras estén en poder de la Administración, aunque sí son objeto de tráfico jurídico y, por tanto, pueden ser aportados para formar el capital de una sociedad, previa declaración de alienabilidad y el correspondiente expediente de enajenación. Cuestión distinta será la valoración económica de los mismos.

Para aquéllos casos en que no se pueda aportar la titularidad del bien o no se quiera, hay una clase de aportación que es la concesión administrativa. Ésta permite obviar esta dificultad puesto que lo que se aporta y se valora es la concesión y no el bien o derecho objeto de la misma.

Junto a lo anterior, hay que tener en cuenta que, en este tipo de sociedades, el status jurídico político del socio no viene dado tanto por la aportación al capital como por la clase de socio, debido a que legalmente las aportaciones de cada socio no podrán exceder de un tercio del capital social salvo, precisamente, los socios públicos que pueden ser titulares de un voto plural ponderado que admite acumular hasta cinco votos sociales, lo que le va a permitir guardar una mayor proporcionalidad entre lo aportado y lo recibido. Igualmente, en las sociedades cooperativas mixtas, el socio público puede ser titular de partes sociales con voto. También en estos casos se establecen límites cuantitativos en relación al porcentaje de votos 
que respecto al total tienen estos especiales títulos, a fin de que el control de la sociedad cooperativa siga en manos de los socios ordinarios.

Por tanto, los entes públicos tienen plena cabida como socios en este tipo de sociedades. Tan solo habría de reivindicarse para éstas como para otros tipos societarios que se reconocieran como una categoría propia y específica cuyo régimen jurídico previera las posibles peculiaridades que la naturaleza pública del socio puede plantear. A fin de garantizar de forma clara e indubitada que la forma jurídica privada se corresponde con la atribución de personalidad jurídica privada que le es propia para que ésta no pueda ser de hecho desplazada por la personalidad jurídica pública del ente administrativo que, en definitiva, estaría actuando por persona jurídica privada interpuesta.

\section{BIBLIOGRAFÍA}

a. Fuentes doctrinales:

ARIÑO ORTIZ, G.: El nuevo servicio público, Madrid: Marcial Pons, 1997. 277 p. ISBN: 84-7248-402-5.

GADEA, E., SACRISTÁN, F. y VARGAS, C.: Régimen jurídico de la sociedad cooperativa del siglo XXI. Realidad actual y propuestas de reforma. Madrid: Dykinson, 2009. 699 p. ISBN: 9788498493795.

GARCÍA RUIZ, E.: La nueva sociedad anónima pública, Madrid: Marcial Pons, 2006. 275 p. ISBN: 84-9768-294-7.

LACRUZ BERDEJO, J. L.: Elementos de derecho civil, I. Vol. III, $3^{\circ}$ ed. Madrid: Dikynson, 1999. 472 p. ISBN: 9788498497380

SANTIAGO IGLESIAS, D.: Las sociedades de economía mixta con forma de gestión de los servicios públicos, Madrid: Iustel, 2010.356 p. ISBN: 978-84-9890-100-9.

SOSA WAGNER, F.: La gestión de los servicios públicos locales," $7^{\mathrm{a}}$ ed. Madrid: Civitas, 2008. 392 p. ISBN: 9788447029013.

VARGAS VASSEROT, C.: "La organización de entidades público-privadas a través de sociedades mercantiles.” En: EMBID IRUJO, José Miguel. El gobierno y la gestión de las entidades no lucrativas público-privadas, Madrid: Marcial Pons, 2012. 277 p. ISBN: 978-84-9768-962-5.

VILLAR ROJAS, F. J.: Privatización de servicios públicos: la experiencia española a la luz del modelo británico. Madrid: Tecnos, 1993. 393 p. ISBN: 84-309-2274-1 
b. Fuentes legislativas.

Real Decreto Legislativo 781/1986, por el que se aprueba el Texto Refundido de las Disposiciones Legales vigentes en materia de régimen local.

Ley 6/1997, de 14 de abril, de Organización y Funcionamiento de la Administración General del Estado.

Ley 47/2003, de 26 de noviembre, General Presupuestaria.

Ley 33/2003 de la Ley de Patrimonio de las Administraciones Públicas.

Ley 5/2011, de 29 de marzo, de economía social.

Ley 27/1999, de 16 de julio, de cooperativas.

Real Decreto 136/2002, de 1 de febrero, por el que se aprueba el Reglamento del Registro de Sociedades Cooperativas.

Real Decreto 1.784/1996, de 19 de julio, por el que se aprueba el Reglamento del Registro Mercantil.

Ley 8/2006, de 16 de noviembre de sociedades cooperativas de la región de Murcia.

Ley 14/2011, de 23 de diciembre, de Sociedades Cooperativas Andaluzas.

Ley 8/2003, de 24 de marzo, de Cooperativas de la Comunidad Valenciana.

Ley4/1993, de 24 de junio, de Cooperativas del País Vasco.

Ley 5/1998, de Cooperativas de Galicia, modificada por la Ley 14/2011, de 16 de diciembre.

Ley 20/2002, de 14 de noviembre de Cooperativas de Castilla-la Mancha. 